\title{
OS LIMITES DA FUNDAÇÃO DE ISAAC ASIMOV: UTOPIA E ANTIAUTORITARISMO
}

\author{
Marcel Cesar Julião Pereira ${ }^{1}$ \\ Gilson Leandro Queluz ${ }^{2}$
}

Resumo: A partir de uma abordagem teórico-crítica este artigo problematiza as noções de ciência e tecnologia presentes no romance Limites da Fundação (1983), de Isaac Asimov, por meio de uma análise discursiva das estruturas narrativas, cronotopos e contexto e vozes sócio-políticas da obra. A obra era a continuação de uma série de contos escritos entre 1944 e 1950, depois agrupados como romances e lançados no formato de trilogia. Acreditamos que a obra Limites da Fundação, trinta anos depois da trilogia original, aborda os temas do determinismo científico e tecnológico em seus contrastes com o livre arbítrio em uma verdadeira retomada retrospectiva das visões e vozes debatidas pelo autor ao longo da obra originária. Ao confrontar suas posições anteriores à sua nova visão de mundo frente as transformações sociais das décadas que separam os romances, Asimov conseguiu dar uma especial relevância crítica e antiautoritária à obra.

Palavras-chaves: Isaac Asimov; Série Fundação; Ficção Científica; Utopia; Autoritarismo.

\begin{abstract}
This article aims to problematize from a theoretical-critical approach the notions of Science and Technology present in the work through a discursive analysis of the narrative structures, chronotopes and context and socio-political voices of the novel Foundation's Edge, by Isaac Asimov. The novel was the continuation of a series of tales written between 1944 and 1950, then grouped as novels and released in trilogy format. We believe that Foundation's Edge, thirty years after the original trilogy, approaches the themes of scientific and technological determinism in their contrasts with free will in a true retrospective resumption of the visions and voices debated by the author throughout the original work. Asimov confronted his previous positions with his new vision of the world in face of the social transformations of the decades that separated the novels, Asimov was able to give a special critical and antiauthoritarian relevance to the work.
\end{abstract}

Key-words: Isaac Asimov; Foundation's Series; Science Fiction; Utopia; Authoritarianism.

INTRODUÇÃO

Em 1983 Isaac Asimov, um dos mais reconhecidos autores de Ficção Científica do século XX e renomado por seu trabalho de divulgação científica, lançou um livro que se tornaria um best-seller de ficção científica, Limites da Fundação, obra que será o objeto de discussão deste artigo. A partir de uma abordagem teórico-crítica vamos problematizar as noções de ciência e tecnologia presentes na obra por meio de uma análise discursiva das estruturas narrativas, cronotopos e contexto e vozes sóciopolíticas da obra. O romance era a continuação de uma série de contos escritos entre 1944 e 1950, depois agrupados como romances e lançados no formato de trilogia, entre os anos de 1951 e 1953 ,

\footnotetext{
${ }^{1}$ Bacharel em Psicologia pela Unviersidade Estadual de Lodrina e Mestre em Tecnologia e Socieade pela Universidade Federal do Paraná.E-mail: marcelcesar@live.com

2 professor da Universidade Tecnológica Federal do Paraná no Departamento de Estudos Sociais e no Programa de PósGraduação em Tecnologia (PPGTE) da UTFPR. E-mail: gqueluz@ gmail.com
} 
mais especificamente Fundação (1951), Fundação e Império (1952) e Segunda Fundação (1953). Acreditamos que a obra Limites da Fundação, trinta anos depois da trilogia original, aborda os temas do determinismo científico e tecnológico em seus contrastes com o livre arbítrio em uma verdadeira retomada retrospectiva das visões e vozes debatidas pelo autor ao longo da obra originária. Ao confrontar suas posições anteriores à sua nova visão de mundo frente as transformações sociais das décadas que separam os romances, Asimov conseguiu dar uma especial relevância crítica e antiautoritária à obra.

\section{FUNDAMENTOS}

Há mais de um século a Ficção Científica tem crescido em popularidade e importância nos países industrializados passando de um obscuro gênero de literatura para um dos principais motores da indústria cultural, como pontua Darko Suvin (1979), crítico literário ${ }^{3}$. Considerando a Ficção Científica enquanto uma forma de discurso, temos os pressupostos do linguista russo Mikhail Bakhtin (1997), para quem todas as formas de discurso são compostas por enunciados em relação dialógica com outros enunciados, que refletem as condições específicas e finalidades da realidade em que foram produzidos. No caso estamos falando de um gênero desenvolvido em diálogo com a ascensão da ciência como paradigma da verdade e a revolução industrial sendo que a medida que estes contextos se desenrolam, emergia tematicamente a tecnologia como objeto de fascínio ou medo nas obras do romance gótico do século XIX (ROBERTS, 2006). Posteriormente, no início do século seguinte, em meio a publicações baratas voltadas ao público adolescente, as pulp magazines, o gênero se consolidaria e receberia seu nome, Ficção Científica.

Inicialmente ignorada pela academia, a Ficção Científica evoluiu enquanto discurso e gênero literário mediada por seu público. Com um público marcado pela presença de técnicos e entusiastas da ciência, autores e editores foram pressionados a produzir contos em que a qualidade literária e científica fosse constantemente aprimorada (ROBERTS, 2006) ${ }^{4}$. Gradativamente o artefato tecnológico vai deixando de ser um mero adereço em uma trama futurística, para se tornar o elemento estruturante das tramas narrativas e construção das personagens, como nota Frederic Jameson (2005), crítico literário e teórico marxiano. Esse amadurecimento crítico começaria a chamar atenção de

\footnotetext{
${ }^{3}$ Teórico de base marxiana, também professor emérito de Literatura na Universidade de MacGill em Montreal

${ }^{4}$ Esta ideia pode ser corroborada pelo relato de Knight (2013) que conta os bastidores e disputas entre fãs e editores de revistas de ficção científica.
} 
pensadores como Hannah Arendt (1998), que acreditava que a Ficção Científica antecipava discussões que somente mais tarde viriam a ser problematizadas.

O uso da tecnologia como adereço na ficção científica tem paralelos com o papel neutro da ciência cujo efeito estava a mercê do uso feito desta para o instrumentalismo. Quando a ciência passa a ter papel estruturante na trama há um diálogo com a visão determinista de que ela, ainda que neutra, é determinante dos rumos da sociedade em direção ao progresso. Com a ascensão do status da Psicologia como ciência, a subjetividade passa a figurar como elemento referencial na Ficção Científica, como nota Jameson (2005). Nota-se nesse processo um diálogo com o substantivismo, corrente de pensamento que problematiza a relação do sujeito com as forças de dominação presentes na tecnologia, vendo que além de determinante a tecnologia era carregada dos valores da sociedade ou grupo que a criaram e não necessariamente os melhores interesses do coletivo ou dos indivíduos. ${ }^{5}$

Como gênero discursivo, é legítima representante do Romance e dialoga com outros subgêneros, como a utopia, a fantasia, e o romance histórico, porém, com grande ênfase em sua resposta à crescente importância da Ciência e da Tecnologia na sociedade moderna. Como gênero literário, Carl Freedman ${ }^{6}$ (2000) nota que a consolidação de seu cânon é exemplo da influência da indústria cultural na produção artística e resultado direto de um embate entre criação, forças de mercado e interação com editores e leitores que participaram ativamente de seu processo de construção.

É notável a presença na Ficção Científica do imaginário tecnológico e suas extrapolações como elemento de estranhamento narrativo. Ao mesmo tempo, a objetividade de uma temática tecnológica e cientifica, demanda um realismo paradoxal. Essa dialética entre estranhamento e cognição foi explorada por Suvin (1979) que via nesse binômio a característica mais marcante do gênero em construção. Para o autor, o gênero é marcado pela construção de um mundo narrado diferente do mundo do autor, aos moldes dos mitos, utopia e viagens fantásticas, porém essa construção era pautada pela lógica e aparência científicas. Para Suvin (1979), ficção cientifica é o gênero literário em que estranhamento e cognição são os elementos essenciais e prevalentes.

É a partir deste conceito paradoxal que Freedman (2000) vai explorar o valor crítico do gênero. Como práticas discursivas, alguns gêneros apresentam maior ou menor afinidade com uma prática dialógica que possibilita a reflexão e críticas emancipatórias. Para Freedman (2000), a ficção científica merece especial atenção, devido às práticas discursivas produzidas por seu contexto e

\footnotetext{
${ }^{5}$ Para um olhar mais aprofundado sobre as principais correntes de pensamento sobre Ciência e tecnologia recomendamos a leitura de Feenberg (2013).

${ }^{6}$ Professor de Teoria da Literatura na Universidade de Baton Rouge, escreve sobre diversas áreas, especialmente Teoria Crítica Marxista, Ficção Científica, filmes e política eleitoral estadunidense.
} 
aglutinadas sob a égide deste gênero. Freedman (2000) identifica três dinâmicas críticas essenciais a ficção cientifica. Primeiro, ao tentar aliar fantasia e Ciência, o gênero é forçado a acentuar o que Bakhtin chamava de heteroglossia, sua pluralidade de vozes. Tanto a hegemonia fantástica é contraposta aos questionamentos da ciência, como a inexorabilidade da logica científica tem que se dobrar ao projeto imaginativo da ficção.

Em segundo lugar há uma dinâmica utópica, que ao construir um lugar diferente do mundo do autor o faz a partir deste. Jameson (2005) vai corroborar o autor, propondo que mesmo se distanciando da realidade, é a partir desta que constrói seus contrastes dando voz às esperanças e sonhos do presente ${ }^{7}$. Ao propor um lugar melhor, ou pior no caso das distopias, as diferenças com a realidade são evidenciadas e muitas questões naturalizadas são problematizadas.

Uma última correlação que Freedman (2000) considera de valor crítico é sua afinidade com o Romance Histórico. Do mesmo modo que este explora a historicidade do presente pela problematização do passado validado em uma cognição histórica, a ficção científica o faz pela problematização do futuro validado por uma cognição científica. A ficção é inscrita na realidade pela demanda da coerência científica.

AUTOR E OBRA

Entre os autores mais representativos do século XX encontra-se Isaac Asimov, que além de ser apontado como um dos mestres da Ficção Cientifica, destacou-se por sua atuação como divulgador e advogado da racionalidade científica. Considerado um dos três grandes autores da Ficção Científica, junto com Heinlein e Arthur C. Clarke, bem como um dos mais prolíficos de todos os tempos - com cerca de 500 livros de sua autoria ${ }^{8}$ - teve um papel privilegiado nos processos que consolidam o cânon do gênero, bem como seus pressupostos (FREEDMAN, 2005).

Seu nome é fortemente associado a discussão sobre robótica, termo que cunhou em seus contos sobre robôs sendo autor das três leis da robótica ${ }^{9}$, princípios que pautavam o funcionamento

${ }^{7}$ Jameson (2005) vai trabalhar a Ficção Científica a partir da hermenêutica de Ernest Bloch traçando a correlação entre Ficção Científica e o princípio da esperança presente no impulso utópico.

${ }^{8}$ Seiler (2018) aponta 506 obras atribuídas a Asimov, porém, algumas são reimpressões. Segundo Freedman (2005), seriam 481 obras publicadas, mas destas apenas cerca de 200 podem ser "indiscutivelmente" consideradas obras únicas e de autoria exclusiva de Asimov, pois muitas são antologias, coautorias, organização de coletâneas ou reedições com novos formatos ou ordenamento. Ainda assim um número impressionante.

${ }^{9} \mathrm{Um}$, um robô não pode ferir um humano sob nenhuma circunstância - e, como corolário, não deve permitir que um ser humano seja ferido por inação de sua parte. [...] Dois, [...] um robô deve seguir todas as ordens recebidas por um ser 
das máquinas em seus contos. Sua consagração se deu em grande parte pela Trilogia da Fundação (1951-1953), um conjunto de contos e romances sobre a Psico-história ${ }^{10}$, uma tecnologia social ${ }^{11}$ desenvolvida por um matemático que seria capaz de por meio de complexas equações matemáticas, cujas variáveis são as forças históricas, prever e manipular o destino da humanidade.

Os primeiros contos que compõem a trilogia marcam uma posição determinante da ciência como motor da sociedade e caminho unilinear e inexorável do progresso. Nos contos, Hari Seldon, havia descoberto por meio de seus cálculos o inevitável colapso do Império Galáctico - que há vinte mil anos havia se estabelecido - bem como os trinta mil anos que transcorreriam até que um novo império se levantasse após uma era de caos. Também por seus cálculos o cientista prevê um caminho, que ficaria conhecido como o Plano Seldon, para se reduzir o crepúsculo da civilização para apenas mil anos. A única saída seria o estabelecimento de duas fundações nos extremos da Galáxia ${ }^{12}$ com os mais brilhantes cientistas que, resolvendo uma série de desafios previstos ou planejados por Seldon, seriam as sementes de um novo e ainda mais grandioso império baseado no poder da ciência e tecnologia.

O primeiro romance, Fundação (1951), capturara no contexto histórico um espírito otimista que via na Ciência e na Tecnologia um caminho rumo à paz que estava abalada pelos horrores da Segunda Guerra Mundial. Como nota Käkelä (2016), sob a influência de seu editor, John Campbell, Asimov e outros autores de sua época privilegiaram uma noção iluminista na qual um líder guiado por princípios acima dele, da racionalidade e da moral, poderia conduzir a sociedade rumo ao progresso, mesmo que isso significasse certo uso de autoritarismo e manipulação.

Por outro, Asimov fazia parte dos Futurians, grupo de escritores de Ficção Científica que se autoidentificavam como comunistas. Apesar de sua formação em Ciências Exatas e a pressão editorial, a trilogia vai gradativamente se aprofundando nas questões sociais da Tecnologia, o que talvez possa ser atribuído às influências por vezes contraditórias do autoritarismo de Campbell e o espírito revolucionário dos Futurians.

\footnotetext{
humano qualificado desde que não entre em conflito com a regra 1. [...] Três: um robô deve proteger sua própria existência desde que não entre em conflito com as regras 1 e 2. (ASIMOV, 1942, p. 100).

${ }^{10}$ Mais que um artefato ou uma nova Tecnologia, a Psico-história problematiza a própria historicidade da Ciência e Tecnologia como motores da sociedade. Nos contos e romances que compõem a série, é a chama para transformar o destino da Galáxia, rumo ao progresso e ao triunfo da civilização como nunca vistos até então.

${ }^{11}$ Usado aqui no sentido de "engenharia social", constitui uma parte específica do biopoder que, aplicando métodos e conhecimentos das Ciências Sociais sobre um problema social específico, levanta informações e desenvolve análises para uso político com o propósito de governar indivíduos e populações (LEIBETSEDER, 2011). O termo foi utilizado pela primeira vez por Albion W. Small (1898).

12 Sob o pretexto de publicar uma enciclopédia com todo o conhecimento acumulado pela Galáxia, Hari Seldon estabelece a Primeira Fundação em um canto remoto da Galáxia, reunindo um time com os mais brilhantes cientistas de cada área do conhecimento tecnológico.
} 
A ciência como grande guia da humanidade vai cedendo espaço a um clima bélico, com o acirramento da Segunda Guerra que culminaria com a queda de Berlim e pouco tempo depois a detonação das bombas de Hiroshima e Nagasaki. Por intervenção de Campbell, que queria ver Asimov lidando com uma situação em que a Ciência falhasse, o segundo romance, Fundação e Império (1952), tem como grande antagonista dos cientistas da Fundação, um mutante com poderes de controlar as emoções, única força capaz de desestabilizar a racionalidade as forças históricas.

Terminado a guerra, o conflito entre Estados Unidos e União Soviética se aprofunda dando início a Guerra Fria, que na trilogia se traduz no terceiro romance, Segunda Fundação (1953), como uma intensa desconfiança entre as duas fundações ${ }^{13}$ planejadas por Seldon. A Primeira Fundação era baseada nas ciências tecnológicas, tendo primeiramente sustentado sua expansão política no uso da tecnologia como religião e na crença de seu destino manifesto de ser a origem do próximo império galáctico. Já a Segunda Fundação, envolta em mistério, era a cátedra das ciências mentais, destinada a monitorar o plano de Seldon, utilizando a Psico-história aliada à sua capacidade de controle mental.

Até então existindo em segredo e mencionada como mito, a Segunda Fundação é forçada a revelar sua existência e extensão de seus poderes para derrotar o mutante e reestabelecer o Plano Seldon. Este evento, não planejado originalmente, instala um clima de desconfiança na Primeira Fundação que em muito lembra o Red Scare, o medo da ameaça comunista que se instalou nos Estados Unidos do pós-guerra. Com o acirramento das tensões entre as fundações, a ciência que era caminho unilinear rumo ao progresso se torna espaço e instrumento de luta entre duas posições conflitantes. Desconfiança, medo e sacrifício marcam o fim dos contos que formam a trilogia.

\section{LIMITES DA FUNDAÇÃO}

Os anos que se seguem assistiriam um acirramento dos conflitos entre capitalismo e comunismo no desenrolar da Guerra Fria. Ao redor de todo o mundo, as pessoas começariam a se levantar e lutar por direitos civis e por novas formas de fazer política. Os dois blocos, liderados pelos Estados Unidos e pela União Soviética, teriam que lidar com os questionamentos que eram postos.

\footnotetext{
${ }^{13}$ A Segunda Fundação surgiria apenas depois da Psico-história falhar, com a missão de utilizando sua tecnologia mental, em analogia a uma caricatura das ciências humanas, colocar o plano de Seldon de volta em curso, sendo seu destino controlar o novo império que se construía.
} 
Toda essa ebulição política influenciou a Ficção Científica das décadas de 1960 e 1970 do século XX e impactaria a retomada da história da Fundação na década de 1980.

Pressionado por sua editora (ASIMOV, 1982), Asimov escreve uma sequência à trilogia, mas agora, autor consagrado, gozando da liberdade que sua fama lhe concedia. Por outro lado, o autor tinha vários desafios a vencer. O mundo havia passado por várias transformações, o público e a ficção científica já não eram mais os mesmos e o próprio autor, trinta anos depois, não era mais o mesmo, e o novo romance deveria dialogar com a trilogia escrita em uma outra realidade. Como pontua Asimov (1981), a trama cada vez mais complexa dificultava o desenvolvimento de novas histórias sem gerar problemas de consistências, além de ter perdido o entusiasmo quanto as ideias originais de Fundação. Ainda segundo Asimov (1982), a saída seria apelar para o que James Gunn, escritor e crítico de Ficção Científica, havia apontado como uma das qualidades da série, permuta e reversões de ideias.

Clyde Wilcox ${ }^{14}$ (1990) pontua que a trilogia e os livros escritos na década de 1980 se encontram nos extremos da Guerra Fria, o que proporcionou contextos sócio-políticos diversos. Segundo Wilcox, de um momento histórico para o outro houve um aumento da percepção da diversidade dentro do comunismo associados a redução da tensão da Guerra Fria. Internamente, a politização da sociedade estadunidense após a década de 1960 aumentou a ênfase na política interna dos Estados Unidos. Estes dois fatores juntos teriam criado o cenário ideal para uma obra de ficção que debatesse a política interna dos Estados Unidos em paralelo as nuances e possibilidades de uma política comunista.

Limites da Fundação captura esse momento histórico ao nos apresentar dois mundos, a Primeira e Segunda Fundação, que confiantes na sua interpretação do Plano Seldon acreditavam ser o epicentro do próximo Império. Como os Estados Unidos, a Primeira Fundação tinha sua força no avanço tecnológico que alavancava seu domínio econômico e político, e compartilhava a crença na liberdade do indivíduo guiado pelos valores do progresso. A Segunda Fundação, como a União Soviética, guiava seu avanço tecnológico pela supremacia das Ciências da Mentais, planejando cada passo em direção ao grande plano, mesmo que ao custo das ambições individuais.

Ambas silenciosamente, disputavam a hegemonia e controle desse novo Império que se formava acreditando ser sua interpretação do Plano Seldon a melhor alternativa para a Galáxia. Em meio a toda essa confiança em seus sistemas, dois jovens políticos - Trevize e Gendibal respectivamente na Primeira e Segunda Fundação - desconfiam que há algo errado no Plano Seldon.

${ }^{14}$ Professor de Política Americana e Comparativa na Universidade de Georgetown no Qatar. 
A propagada precisão de como o Plano progride não seria matematicamente ou logicamente possível, o que os leva a conclusão de que o mesmo é um engodo.

Cada um dos heróis tem que enfrentar em seu mundo a fúria de sistemas desenhados para defender sua versão do Plano de Seldon. Na primeira fundação, o Plano é utilizado como um limitador para liberdade de expressão e ferramenta autoritária, ninguém pode questionar o Plano. Na Segunda Fundação o Plano, revestido da neutralidade e precisão científica só pode ser melhorado pelo uso da ciência, sem espaço para questionamentos de outra ordem. A disputa política é reduzida a dimensão técnica. Por fim, são banidos sob o pretexto de averiguarem se suas suspeitas são verdadeiras e cada qual parte em sua busca.

Usando os poucos fragmentos de informações confiáveis dentro dos vários mitos, Trevize, seguido por agentes de Gendibal, encontra um planeta chamado Gaia. Chegando ao planeta, descobre que seus habitantes são dotados de uma habilidade psíquica tão poderosa e avançada que se fundiram como uma única consciência coletiva, da qual até os seres inanimados fazem parte. "Eu sou Gaia. [...] E o solo. E aquelas árvores. E aquele coelho, ali na grama. E o homem que vocês podem ver entre as árvores. O planeta todo, e tudo nele, é Gaia” (ASIMOV, 2012, p. 335). Tudo faz parte dessa gigantesca consciência coletiva, atuando em todos os processos de decisão e execução.

Para Asimov, as duas alternativas até então dadas estavam fadadas ao fracasso. Segundo Wilcox, esta postura reflete uma terceira influência do contexto político sobre o autor, os movimentos de contracultura que demandavam uma democracia participativa. Se a Primeira e a Segunda Fundação são um paralelo para o Primeiro e Segundo Mundo, Asimov via em ambos aspectos positivos e negativos, entretanto, nenhuma seria uma forma de garantir um futuro. Asimov propõe uma terceira via, Gaia, a mais radical democracia participativa, "uma visão de um universo em que toda matéria é inteligente e participa nas decisões que afetam seu futuro" (WILCOX, 1990, p. 61, tradução nossa).

A ideia de um planeta como organismo único, bem como o nome, foi emprestada de outro bioquímico, James Lovelock que junto com bióloga Lynn Margulis desenvolveu a Hipótese de Gaia. A partir de estudos sobre a atmosfera de Marte, Lovelock e Margulis (1974) chegam à conclusão de que a vida tem uma função de gerar homeostase planetária integrando tanto seres vivos como inanimados, como se todo o planeta fosse um único organismo. Pode parecer óbvio que a presença de matéria viva interfira na geodinâmica, mas até então as teorias evolucionistas, tal qual os pesquisadores em busca de vida em outros planetas, entendiam que era a presença de oceanos e uma atmosfera ideal que permitiam o surgimento da vida. A Hipótese de Gaia, partindo do fato de planetas que tiveram oceanos e atmosfera favorável, mas não desenvolveram vida perderam essas características, inverte o 
axioma, afirmando que a vida é a causa e manutenção dessas características que só fariam sentido em modelo evolutivo quando ao invés de se tomar as espécies individualmente, se considerasse o planeta todo como um único organismo (LOVELOCK, 2000).

Extrapolando este conceito, a consciência coletiva de Gaia teria sido formada ao longo de séculos com a ajuda de robôs, que já haviam abandonado o planeta. Conforme se desenvolvia a consciência coletiva, se expandia seu conhecimento sobre o destino da humanidade. Percebiam que se aproximava um confronto inevitável entre a Primeira e a Segunda Fundação. Triunfando a Primeira, a humanidade "será um império militar, estabelecido por conflito, mantido por conflito e, eventualmente, destruído por conflito", enquanto a vitória da outra levaria a um "império paternalista, estabelecido por cálculos, mantido por cálculos e em perpétua semivida por cálculos" (ASIMOV, 2012, p. 382-383). Como uma Galáxia aos moldes da Primeira Fundação ou da Segunda, por razões diferentes, estaria fadada ao fracasso, Gaia propunha que sua forma de existir, uma consciência coletiva, se estenda por toda a Galáxia.

Os valores éticos e morais que pautavam Gaia a obrigavam a proteger a humanidade como um todo, bem como cada um de seus indivíduos. Como isso significaria uma profunda intervenção na própria natureza humana, não podiam tomar essa decisão sozinhos. Estavam em uma encruzilhada ética, não podiam deixar a humanidade seguir seus caminhos totalitários ou destrutivos, do mesmo modo que não podiam impor uma solução.

O resultado é que agora estamos impotentes. Não podemos impor nossa visão de uma Galáxia viva ao quintilhão de seres humanos e a incontáveis outras formas de vida, e possivelmente causar mal a vastos números delas. Tampouco podemos ficar alheios e assistir enquanto a maior parte da Galáxia se destrói em um conflito que poderíamos ter evitado. Não sabemos se ação ou inação seria menos custoso para a Galáxia; se escolhêssemos ação, tampouco sabemos se apoiar Terminus ou Trantor seria menos custoso para a Galáxia (ASIMOV, 2012, p. 385).

Gaia precisa que algum agente externo a si e parte da humanidade faça essa escolha, quebrando o balanço do impasse em que se encontrava. Por uma série de manipulações psico-históricas e de controle mental, membros da Primeira e Segunda Fundação foram atraídos a Gaia, para que se confrontassem e uma caminho fosse escolhido. Asimov, cria uma cena de um verdadeiro julgamento, em que cada lado expõe os motivos pelos quais acredita que seu sistema é o melhor e o porquê as outras duas opções são problemáticas. Uma vez escolhido um dos três caminhos, Gaia utilizaria todo seu poder para guiar a Galáxia seguramente rumo ao futuro. 


\section{ESTRUTURA COMPOSICIONAL}

O livro Limites da Fundação é o primeiro da série Fundação escrito originalmente na forma de romance o que lhe garante maior unidade. Ao contrário da estrutura de capítulos que contavam episódios de uma civilização, como aventuras separadas, o romance acompanha as personagens em suas viagens de busca e transformação privilegiando aspectos subjetivos da trama. Há um paralelismo entre as narrativas dos heróis, ressaltando as semelhanças na percepção sobre sistemas políticos tão distintos. São jovens políticos ambiciosos, confiantes em suas habilidades e competência; têm um forte opositor político e parecem ser capazes de usar de qualquer subterfúgio para conquistar ou manter o poder, mas que, de certa forma, se revelam leais a seus ideais. Os heróis partem em curso de colisão com a resolução de seus conflitos e ambos são transformados pelo encontro. Há um tom de déjà vu na forma como o conflito se resolve por meio de um deus ex machina ${ }^{15}$. Na trilogia essa função era exercida pela mão invisível do Plano Seldon, mas em Limites da Fundação essa função é devolvida ao ser humano e seu livre arbítrio.

As estruturas narrativas escolhidas por Asimov refletem as vozes debatidas pelo autor e com o autor. Como nota Käkelä (2016), o romance começa com o questionamento da premissa principal da trilogia e faz uso de uma jornada em busca de respostas. Nessa jornada, reflete sobre o passado da humanidade que os levou até aquele ponto e confronta os futuros possíveis. Sem uma resposta óbvia, monta um tribunal, no qual os argumentos de cada visão são debatidos. Mais do que refletir as vozes em diálogo, as escolhas estruturais refletem uma mudança no próprio enquadramento filosófico do autor. Aos moldes de uma Teoria Crítica, de um autoquestionamento, se parte para busca por respostas que fundamentaram o embate das ideias, em que são reconhecidos os argumentos e contexto de cada ideia debatida e a escolha a partir de um ato de emancipação informada.

\section{LINGUAGEM}

Outro aspecto importante, a linguagem na trilogia vai variar entre matematizada e militarizada, sendo ambos os recursos utilizados para formar uma narrativa que isenta o autor de dar maiores explicações sobre uma construção. De modo geral, essa era, e é, uma prática comum na Ficção

\footnotetext{
15 “A expressão - um deus saído da máquina - refere-se, como sabemos, a um mecanismo do teatro da Grécia antiga, em que um enredo complicado era resolvido por via de uma agência externa e improvável, literalmente um deus que descia até ao palco com a ajuda de um guindaste" (GOMES, 2012, p. 3).
} 
Científica que conta com a familiaridade de seu público com o megatexto ${ }^{16}$ para evitar longas explicações científicas, ou simplesmente evitar explicações que não tem. Enquanto os romances da trilogia pareciam defender o uso dessa linguagem científico-matemática, em Limites da Fundação, junto com a linguagem política, são apresentadas como instrumentos que compartilham o tom autoritário. Uma é marcada pelos jargões legislativos e outra pela racionalidade matemática, como fonte de autoridade. Na linguagem, política e matemática se enfrentam em paralelo, como instrumentos de dominação e autoritarismo, que privilegiam aqueles que as dominam.

Outra questão que podemos explorar no uso da linguagem é a despolitização do diálogo sob o pretexto científico. Arendt (1998) aponta que a ascensão de uma linguagem matemática científica se deu em prejuízo da dimensão política da linguagem. Como exemplo, a autora menciona que a linguagem científica não impediu os cientistas de desenvolverem a bomba atômica que seria usada para extermínio das massas. A resposta matematicamente correta nem sempre é a resposta correta, pois excluí a dimensão política no processo de tomada de decisões da humanidade que é especialmente plural. Isso é claro, no romance, nos debates da Mesa dos Oradores, em que as disputas políticas motivadas por ambições pessoais se dão em termos de comparar a melhor matemática. Apesar da precisão algébrica, suas conclusões os levam ao erro interpretativo e à incapacidade de equacionar o jogo político que reside além da matemática.

Uma última consideração quanto à linguagem utilizada em Limites da Fundação se refere a Gaia. O planeta é apresentado na obra como um organismo vivo formado por tudo que sobre ele se encontra, bem como o planeta em si. Essa forma de existência tem três dimensões que Asimov apresenta não só com argumentos, mas também com recursos linguísticos: Gaia, a consciência coletiva de Gaia como distinta dos indivíduos que a compõem, tratada na terceira pessoa do singular; Gaia, como o grupo de indivíduos que a compõem, tratado na primeira pessoa do plural; e Gaia enquanto cada indivíduo distinto e ainda assim interconectado aos demais, tratado na primeira pessoa do singular.

— Sei, Trev, que você suspeita que eu/nós/Gaia estava interessada em você.

—Eu/nós/Gaia? — perguntou Pelorat, mansamente.

EIa se virou e sorriu para ele.

- Temos toda uma rede complexa de pronomes diferentes para expressar os tons de individualidade que existem em Gaia. Poderia explicá-los para vocês, mas, até lá,

\footnotetext{
${ }^{16}$ De acordo com Broderick (1995) o megatexto da ficção científico é construído pelo próprio conjunto de textos do gênero que ao longo do tempo estabeleceram imagens, tropos, estilos e recursos recorrentes e acabam, muitas vezes por estabelecer regras que pautam os autores de ficção científica.
} 
'eu/nós/Gaia' transmitirá minhas intenções, mesmo que de maneira um tanto desengonçada (ASIMOV, 2012, p. 332).

O uso desse recurso tem duas consequências, a primeira expor a diferença entre a forma como compreendemos o indivíduo, o outro e o grupo com a forma proposta por Gaia. O segundo desdobramento é expor, outra vez, as limitações da linguagem. Se anteriormente os limites explorados eram nossa capacidade linguística de expressar conceitos matemáticos, desta vez era a limitação da linguagem em expor a própria subjetividade. Esse tipo de discussão encontra ressonância em discussões identitárias que percebem no uso binário de pronomes masculinos e femininos um problema para se referir a pessoas que não se enquadram entre ou em nenhum dos polos desse binário.

\section{CRONOTOPO}

Uma dimensão fundamental na caracterização de uma narrativa é a forma como representa o tempo e o espaço, o que Bakhtin chamava de cronotopo ${ }^{17}$ (FIORIN, 2016). A forma como as pessoas organizam, compreendem e descrevem o tempo e o espaço é uma forma histórica, varia de um povo para outro e de um tempo para outro. As diferenças estão impregnadas no discurso e refletem formas históricas e subjetivas de compreender a realidade. O tempo e o espaço em Limites da Fundação se organizam em torno do tempo de espaço do sujeito. Apesar dos contos que compõem os demais romances também serem organizados de tal forma, o seu agrupamento como romances criou saltos no tempo e espaço que tiravam a centralidade do tempo do sujeito, deslocando-a para o processo psicohistórico em si, e situava a narração no espaço da fronteira, gerando um efeito épico da história da expansão de um povo.

O arranjo do cronotopo vinha ao encontro do argumento que a voz do autor tentava defender, a de que as forças históricas e da Ciência se sobrepunham à existência do sujeito, que mesmo sendo dotado de seu livre arbítrio não passava de uma peça dentro de uma trama, quando se olha grandes espaços de tempo espalhados pelo espaço das estrelas e das multidões.

Em Limites da Fundação há uma reversão desse processo e as centenas de anos do Plano Seldon e a vastidão da Galáxia são compreendidas pela perspectiva do sujeito. Um exemplo está no primeiro capítulo do romance, o herói se encontra saindo do espaço majestoso em que as profecias de

${ }^{17}$ Bemong e Boghart (2010) destacam que Bakhtin não chega oferecer uma definição fechada de cronotopo, em geral sinaliza o conceito e parte para diferenciar os diferentes tipos de cronotopos. 
Seldon sobre o presente e o futuro eram declaradas. O espaço composto por prédios monumentais é construído de forma a transparecer uma suposta ancestralidade.

— [..] Veja a Galeria Seldon. No início, na primeira crise nos dias de Salvor Hardin, era apenas o Cofre do Tempo, um pequeno auditório no qual a imagem holográfica de Seldon aparecia. E só. Agora é um mausoléu colossal. Mas há uma rampa de campo de força? Uma esteira? Um elevador gravitacional? Não, apenas estes degraus, e descemos e subimos por eles assim como Hardin precisaria ter feito. Em tempos estranhos e imprevisíveis, nos agarramos, apavorados ao passado.

— Existe algum componente estrutural visível que seja metal? - Continuou Trevize abrindo um braço, enfatizando o que dizia. - Nenhum. Não faria sentido ter algum, pois, na época de Salvor Hardin, não havia nenhum metal nativo e quase nenhum importado. Chegamos a instalar plástico antigo, rosado por causa da idade, quando construímos essa pilha imensa, para que visitantes de outros mundos pudessem parar e dizer: 'Galáxia! Que adorável plástico antigo!'. Eu lhe digo, Compor, é uma farsa (ASIMOV, 2012, p. 17-18).

Asimov inicia sua narrativa estabelecendo na própria composição arquitetônica e seus materiais de construção o argumento central do romance, a ideologia que sustenta a Fundação é uma farsa. O espaço narrativo é o espaço do entorno do sujeito e não o espaço político dos fundacionistas como civilização. Nesse espaço particular, a grandiosidade estatal conversa com o sujeito e é filtrada e interpretada por sua ótica. A voz do sujeito, que via o engodo das estruturas pretensiosas, se sobrepõe à voz monológica da ideologia que buscava conectar o passado e o futuro.

Para afirmar que o Plano Seldon e todo sistema derivado dele são uma falácia, ele aponta para a falsidade que os envolve. O prédio simples que um dia existiu foi substituído por algo muito mais complexo e elaborado, colossal, capaz de impressionar quem o visitava e reafirmar o poder da Fundação. Porém, era preciso que a Fundação fosse constantemente legitimada pela herança intelectual de Seldon, sendo necessário fazer parecer que o templo colossal fosse originalmente um legado do passado.

A trilogia costumava descrever a Galáxia em termos de centro e periferia. Havia uma polarização entre Trantor, antiga capital do império no centro da Galáxia, e a periferia bárbara onde se encontrava a Fundação. Essa distinção era representada pelo contraste entre um planeta coberto totalmente por metal, prédios e povoado por bilhões, e os planetas da Fundação, em geral pacatos e por vezes bucólicos. Já em Limites da Fundação, ao invés de demonstrar a centralidade de Trantor pelos indicadores de sua vida sociopolítica, sua centralidade é evidenciada pela percepção subjetiva 
de um céu estrelado, um céu possível apenas no centro da Galáxia, mas, ainda assim, um céu que depende de um sujeito que o contemple.

Por fim uma mudança importante na representação da Galáxia é a inclusão da dimensão temporal, antes apresentada como localizações pelas quais a narrativa se deslocava. Em uma passagem do livro, as personagens contemplam a Galáxia a distância e utilizam o computador para acelerar o tempo da imagem, permitindo que se perceba seu movimento. "A Galáxia estava se movendo. Lentamente, de maneira titânica [...]" (ASIMOV, 2012, p. 83).

A representação do todo espacial ganha vida na dimensão temporal. O todo cronotópico galáctico se manifestava apenas nos encontros da fronteira do espaço, do centro da Galáxia e nos saltos históricos e nos saltos do hiperespaço, um todo relatado e racionalizado, épico e filosófico. Em Limites da Fundação, o tempo e o espaço formam um todo cronotópico da Galáxia que se apresenta viva na perspectiva subjetiva. Não é apenas o tempo que dá movimento e vida à Galáxia, mas também o olhar subjetivo do herói que interpreta em seu movimento a analogia da vida. Ação, tempo e espaço formam uma amálgama viva e pulsante no olhar subjetivo.

Outra questão cronotópica importante para a discussão de uma utopia, são os recursos pelos quais Gaia, a utopia final é separada e conectada com o todo galáctico. Em Gaia, o espaço da fronteira, do eu e do outro, da expansão, é substituído por um espaço da totalidade, da utopia final. Se o espaço utópico, segundo Jameson (2005), se constitui em seu distanciamento como sistema hermético distinto da realidade, seja a realidade geográfica, temporal ou do corpo, e por uma solução totalizante desse espaço distinto, Gaia é a utopia extrema, pois seu sistema hermético é sua própria totalidade, a solução utópica de Gaia é a totalidade. Primeiro como organismo único, Gaia é um sistema isolado pelo uso de seu grande poder para apagar todos os registros sobre si e impor aos planetas vizinhos uma sombra de medo de sequer pensar sobre sua existência. Internamente, Gaia viveu alheia à Galáxia até se tornar ciente de que outra consciência coletiva, com ambições totalizantes, começava a se formar na Segunda Fundação. Em seguida, Gaia propõe a utopia final, Galáxia. Ao estender sua forma de existir, em que a harmonia se dá pela fusão de todos os seres, a toda a Galáxia, Gaia se tornaria um sistema isolado não pelo distanciamento, mas pela inexistência de algo fora do sistema, a totalidade final.

Asimov propõe a construção de um espaço utópico para a alteridade pela eliminação, pela negação do espaço que pode ser reconhecido como a referência e espelho dessa alteridade. No caso de Fundação, estamos falando de utopias que se sobrepõem e colidem, visto que se Gaia e Galáxia são o espaço utópico em relação à Fundação, esta é o espaço utópico isolado da realidade terrena. $\mathrm{O}$ autor aplica o recurso do forasteiro visitando uma terra estranha em diversos momentos para debater as 
características utópicas dos topos que constrói, de forma bastante elaborada. São personagens de uma utopia, encontrando a alteridade em outra utopia. O que chama atenção no uso desse recurso é como ele contrasta elementos que podemos identificar com nossa realidade presente, em cada uma das utopias que colidem com os elementos de estranhamento delas próprias. Nenhum elemento dos confrontos utópicos pode ser totalmente designado como alienígena a nós, assim como nenhum pode ser considerado um cognato de nossa experiência terrena.

Essa construção do encontro utópico foi possível, ou talvez necessária, por uma questão que o autor já apontava no primeiro romance, mas retornaria com forma marcante nas obras subsequentes, a ausência da Terra. A Galáxia de Fundação se caracteriza como um cronotopo utópico distinto do nosso por se distanciar de nossa própria existência. Não há um aventureiro da Terra para questionar o mundo de Fundação. Não estamos distantes de Fundação apenas no tempo, estamos distantes no espaço, porque nesse mundo não existimos mais como espaço vivo.

\section{VOZES SOCIOPOLÍTICAS}

Em Limites da Fundação a noção de governantes iluminados e altruístas construída na trilogia cai por terra e soa irônica para ambos os modelos propostos. Tanto a Primeira Fundação, que desejava ser senhora de seu próprio destino, não acreditava na pureza de intenções da Segunda, como os próprios oradores, os políticos desta, não acreditavam que qualquer grupo pudesse cumprir a tarefa de tal forma. Ou seja, nem mesmo a Segunda Fundação, que acreditava ser um grupo altruísta que governaria em nome do bem maior, acreditava que era possível tal grupo existir.

A descrição da Segunda Fundação na obra é de uma sociedade igualitária no que se refere aos bens e conforto de seus membros. Ainda assim, os oradores, como grupo, formam uma elite com o privilégio do poder. Há um preço a pagar, uma vida de simplicidade, uma aparente humildade, mas as vicissitudes da vaidade são reinventadas nas disputas políticas internas e organização meritocrática subjacente às relações entre os oradores. O único privilégio político seria do primeiro orador, que tinha a prerrogativa de falar primeiro, o domínio sobre a Psico-história era um fator diferencial entre os oradores. Havia uma disputa entre eles. A aparente nobreza, humildade e simplicidade mascaravam uma sociedade tão competitiva quanto a Galáxia que tentavam dominar. A neutralidade e a falta de interesses pessoais apenas assumiam novas formas e cores, mas não se fazia ausente. 
A assembleia da Mesa não estava completa.

$[\ldots]$

A mente de Delarmi levou um breve instante para pensar na questão conforme olhava de rosto em rosto e de mente em mente até que, sardonicamente, encarou o assento vazio, o assento do novato.

Ela estava satisfeita com a falta de simpatia em relação a Gendibal. O jovem, ela sentia, tinha todo o charme de um inseto, e merecia ser tratado como tal. Até agora, somente sua inquestionável capacidade e talento haviam impedido que alguém propusesse abertamente um julgamento por expulsão [...].

Entretanto, o óbvio descaso de perder uma assembleia da Mesa era pior do que qualquer ofensa, e Delarmi estava contente de sentir que o interesse por um julgamento avançava consideravelmente (ASIMOV, 2012, p. 130-131).

Delarmi, representa a articulação política e a prevalência de valores sobre uma suposta neutralidade. $\mathrm{O}$ autor afasta as suspeitas de corrupção por interesses escusos de fundo econômico. A personagem é uma idealista que de fato crê na ideologia que defende e ainda assim é capaz de manipular e entrar no jogo político em defesa de interesses próprios. Asimov demonstra que, mesmo quando os valores puros de uma ideologia voltada ao bem maior são mantidos, há espaço para a imposição de uma satisfação pessoal. Mesmo o bem maior não é imune ao egoísmo e à centralização. Não é possível crer que um poder absoluto, por mais bem-intencionado que seja, venha a ser capaz de se desprover de impulsos egocêntricos. De certa forma, o autor reconhece a possibilidade de uma organização, ou uma elite, ser honestamente movida pelo propósito de um bem maior, ainda assim, na relação da estrutura de dominação, o desejo de poder se faz presente

É, essencialmente, no novo enfoque dado à Mesa dos Oradores que reside a crítica de Asimov à Psico-história em Limites da Fundação. A Primeira Fundação abandonou os preceitos da Psicohistória, restando apenas um Plano Seldon mitificado que, como religião, não serve à autonomia dos que o seguem, mas a justificação do autoritarismo, o que resta da Ciência quando seus preceitos a abandonam. A Mesa não só acredita como defende e vive os preceitos psico-históricos e, ainda assim, seu sucesso, mascara seu fracasso. A representação da Mesa foi progredindo do paraíso eutópico abnegado para uma utopia crítica e finalmente uma antiutopia. O futuro é Gaia. Um futuro em que as equações psico-históricas não são mais uma tecnologia misteriosa serviço de um grupo restrito, mas um instrumento para auxiliar serviços processos de tomada de decisão de uma consciência coletiva governada por sua ética. 


\section{CONCLUSÃO}

Apesar da prevalência determinista nos primeiros contos, ainda na trilogia observamos um diálogo com posturas substantivistas e críticas quanto a relação entre tecnologia e sociedade que se aprofundam em Limites da Fundação. Questões como autoritarismo e manipulação que fazem parte do primeiro romance, Fundação, são justificadas em nome do bem maior. Seus líderes são guiados pelos próprios princípios da ciência, visando progresso e neutralidade, mas surgem como subprodutos a plutocracia e autoritarismo, sendo possível notar uma influência substantivista. Ainda assim, é apenas quando o mutante derrota a Primeira Fundação, no romance Fundação e Império, é que foi rompida de vez a trajetória determinista da Psico-história, revelando a ciência como uma ilusão frágil que pode colapsar sob suas próprias conquistas ou sobre as artimanhas de um sujeito habilidoso.

O clima sombrio com que a trilogia se encerra é convertido no ufanismo alienado com o qual as Fundações veem a si próprias. Trevize e Gendibal são as vozes que a partir da suspeita substantivista das obras anteriores questionam a realidade. Há uma postura teórico-crítica que se acentua quando Limites da Fundação chega a sua catártica cena em que a racionalidade sozinha não pode decidir o caminho da humanidade, é preciso que alguém, dotado de livre-arbítrio faça essa escolha. O papel da técnica é subjugado pelo papel emancipatório do sujeito cientificamente informado como lugar de tomada de decisão.

Tendo em vista todas as transformações identificadas e a forma dinâmica como dialogam entre si, acreditamos que o livro Limites da Fundação de fato é uma obra que privilegia o dialogismo ao fim, mesmo com suas tentativas totalizantes. Vemos uma forte marca de uma teoria crítica à tecnologia representada na passagem do julgamento. Mesmo convicto de suas posturas, o autor as submete a um escrutínio em que suas certezas deterministas do passado são expostas em seus acertos e falhas, bem como suas esperanças utópicas para o futuro o são. $\mathrm{O}$ autor faz uma escolha pelo futuro, mas o faz sem apontar seu caminho como único, como absoluto ou inexorável. O faz como uma escolha, da mesma forma que a evolução tecnológica se faz a partir de escolhas por opções e não pela inexorabilidade da razão ou por uma imaginária e autoritária determinação científica. 


\section{REFERÊNCIAS}

ARENDT, H. The Human Condition. 2. ed. Chicago and London: University of Chicago Press, 1998. ASIMOV, I. Runaround. Astounding Science-Fiction, v. XXIX, n. 1, p. 94-103, mar. 1942.

ASIMOV, I. There's Nothing Like a Good Foundation. In: Asimov On Science Fiction. 1. ed. Garden City, N.Y: Doubleday, 1981. p. 313-317.

ASIMOV, I. The History Behind the Foundation. In: The Foundation Trilogy. 1. ed. London: Littlehampton, 1982. v. 1.

ASIMOV, I. Limites da Fundação. Tradução Henrique B. Szolnky. 1. ed. São Paulo: Aleph, 2012.

BAKHTIN, M. Estética da Criação Verbal. Sao Paulo: Martins Fontes, 1997.

BEMONG, N.; BOGHART, P. Bakhtin's theory of the literary chronotope: reflections, applications, perspectives. In: BEMONG, N. et al. (Eds.). Bakhtin's theory of the literary chronotope: reflections, applications, perspectives. Gent, Netherlands: Ginko, Academia Press, 2010.

BRODERICK, D. Reading by starlight: postmodern science fiction. London; New York: Routledge, 1995.

FIORIN, J. L. Introdução ao pensamento de Bakhtin. São Paulo: Contexto, 2016.

FREEDMAN, C. Conversations with Isaac Asimov. Jackson: University Press of Mississippi, 2005.

FREEDMAN, C. H. Critical theory and science fiction. Hanover: Wesleyan University Press: University Press of New England, 2000.

GOMES, M. R. Deus ex machina_História e Utopia em Isaac Asimov. E-topia: Revista Electrónica de Estudos sobre a Utopia, v. 13, 2012.

JAMESON, F. Archaeologies of the Future: The Desire Called Utopia and Other Science Fictions. [s.l.] Verso, 2005.

KÄKELÄ, J. The Cowboy Politics of an Enlightened Future: History, Expansionism, and Guardianship in Isaac Asimov's Science Fiction. Dissertação-Helsinki: University of Helsinki, 2016.

KNIGHT, D. The Futurians [Kindle Edition]. London: Orion Publishing; e Gollancz eBooks, 2013.

LEIBETSEDER, B. A critical review on the concept of social technology. Socialines technologijos, v. 1, n. 1, 2011.

LOVELOCK, J. A New Look at Life on Earth. Oxford: Oxford University Press, 2000. 
LOVELOCK, J. E.; MARGULIS, L. Atmospheric homeostasis by and for the biosphere: the Gaia hypothesis. Tellus, v. 26, n. 1-2, p. 2-10, fev. 1974.

PEREIRA, M. C. J. Histórias de uma psicologia do futuro: Representações de Ciência e Tecnologia em Fundação, de Isaac Asimov. Dissertação de Mestrado - Curitiba: Universidade Tecnológica Federal do Paraná, ago. 2018.

ROBERTS, A. Science fiction. 2nd ed ed. London; New York: Routledge, 2006.

SEILER, E. A Catalogue of Isaac Asimov's Books. Disponível em: <http://www.asimovonline.com/oldsite/asimov_catalogue.html>. Acesso em: 12 out. 2018.

SMALL, A. W. Seminar Notes: The Methodology of the Social Problem. Division I. The Sources and Uses of Material. American Journal of Sociology, v. 4, n. 1, p. 113-144, 1898.

SUVIN, D. Metamorphoses of science fiction: on the poetics and history of a literary genre. New Haven: Yale University Press, 1979.

WILCOX, C. The Greening of Isaac Asimov: Cultural Changes and Political Futures. Extrapolation, v. 31, n. 1, 1990. 